\title{
Multidimensional Business to Business E-Commerce Maturity Application: Assessment on Its Practicality
}

\author{
Norjansalika Janom1, Mohd Shanudin Zakaria², Noor Habibah Arshad1, Siti Salwa Salleh1, \\ Syaripah Ruzaini Syed Aris ${ }^{1}$ \\ ${ }^{1}$ Information System Department, Universiti Teknologi MARA, Shah Alam, Malaysia \\ ${ }^{2}$ National Defence University of Malaysia, Kuala Lumpur, Malaysia \\ Email: norjan@tmsk.uitm.edu.my, msz@ukm.my
}

Received 28 March 2014; revised 5 May 2014; accepted 21 May 2014

Copyright @ 2014 by authors and Scientific Research Publishing Inc.

This work is licensed under the Creative Commons Attribution International License (CC BY). http://creativecommons.org/licenses/by/4.0/

(c) (i) Open Access

\section{Abstract}

In most countries, Small Medium Enterprise (SMEs) are known as main players in generating domestic-led investment and stimulate economic expansion. They are vital for economic growth and innovation, poverty reduction, local employment and development, and social cohesion. However, in the current digitally-connected trading economy, SMEs have face many new challenges that change the way SMEs business-to-business (B2B) trading operates. Among these challenges ARE the level of B2B e-commerce implementation and utilization that able to facilitate B2B trading process. However, the implementation of B2B e-commerce is being categorized as a system with high degree of difficulty since it involves complexity of the multiple relationships and interactions between trading partners. The interactions are not just complicated by their volume and variation in processes, but also by the complexity inherent in the dependencies exist between different trading parties. Based on this, for SMEs to partake in the B2B e-commerce activities, they need to have attained some reasonable level of maturity or readiness measurement in order to participate in B2B e-commerce initiatives. To overcome this, the robust multidimensional B2B e-commerce maturity application to assess the e-readiness level is needed. This paper describes the development of B2B e-Commerce Maturity Application (BeMA) which involves several distinct sequential exploratory stages. In order to ensure its validity and practicality, the application was evaluated by 35 selected SMEs. Based on the evaluation results, all respondents were agreed on the model usefulness and its practicality. The research believes that the model will provide practical guidance for SMEs to clearly define appropriate method of measuring e-readiness and the recommendation approaches to improve their B2B e-commerce maturity level.

\section{Keywords}

B2B E-Commerce, E-Readiness, Small Medium Enterprises, Maturity Assessment Application, 


\section{Maturity Level}

\section{Introduction}

Small and Medium-Sized Enterprises (SMEs) are often seen as the backbone of the economy for most developing countries in the world. They are vital for the development and innovation of dynamic economies, poverty reduction, employment, and social cohesion. Internationally, there is a growing impetus for the development of strong SMEs sectors as a catalyst for the economic growth and development [1] [2]. Their substantial contributions of $80 \%$ to global economic growth make the SME sector as a major growing force in terms of contribution to GDP, scale of assets, diversification of products, and the creation of employment [2] [3]. In Malaysia, SMEs have historically been the main player in domestic economic activities, especially as a large provider of employment opportunities, and a generator of primary or secondary sources of income for many households. According to SME Annual Report 2009/10, there are more than half a million SMEs in the country, constituting about $99.2 \%$ or $548 \%, 267 \%$ of total business establishments with almost $80 \%$ in the form of micro enterprises. SMEs are a major source of employment, providing jobs for over 3.0 million workers and accounting for $56 \%$ of total employment. However, to ensure the continous success and sustainability of SMEs to be the engine of economy growth, it is important for SMEs to remain competitive and be adaptive in the use of B2B e-commerce technology [4] [5]. Nowadays, compared to other business models, the B2B e-commerce is considered as the most significant in terms of growth, financial contribution and the economic impact [4]-[8]. Considering the fact that $\mathrm{B} 2 \mathrm{~B}$ e-commerce is the most significant source of growth of business on the internet, and the prediction on the ultimate size of B2B e-commerce is enormous, the unsuccessfulness and slow adoption of the B2B e-commerce might have a significance effect on SME in general [9]. The lagging of SME sector in preparing itself to embrace e-commerce, could hinder their resilience and competitiveness, since B2B e-commerce application is able to enhance the effectiveness of upstream and downstream business transactions as well as facilitate trading over regional and geographic boundaries at low costs [4].

However, considering the various constrains of SMEs compared to large organizations in terms of expert, financial and technological resources, failures of such a complex and expensive B2B e-commerce project might affect their businesses. In fact, over the years there are many failure stories in B2B e-commerce project developments that range from insufficient resources in terms of technology, employees, operational, financial to the lack of solid management tools for forecasting, monitoring and evaluating the e-commerce adoption process [10]-[12]. Many organizations are not achieving even minimal levels of B2B e-commerce adoption, raising concerns as to why e-commerce adoption initiatives, including projects led by government, are not more successful [13]-[15]. This highlights the importance for SMEs to know the prerequisite factors before adopting the technology since B2B e-commerce involves high level of implementation risks to the organizations as well as to the trading partners. Understanding the growing process of B2B e-commerce implementation also enhances the ability of organizations to ready, plan and develop their application strategy [4] [13]. Thus, there is a need for an e-readiness model that can determine the $\mathrm{B} 2 \mathrm{~B}$ e-commerce maturity level and its requirements on SMEs.

\section{A Review of E-Readiness Assessment Model}

B2B e-commerce may help an organization to gain competitive advantage over their competitors. However, since some e-commerce related implementations ended in disastrous failures especially among, SMEs therefore need to know their maturity level and every aspect needed to improve themselves before implementing the systems SMEs [12]. Organizations also need to consider their strengths and weaknesses before making decisions to explore new online channels without weakening the existing channels. However, according to [16]-[18], most e-readiness models would require re-designing in order for them to be comprehensive e-readiness assessment tools. The missing robust model of e-readiness that focuses specifically on SMEs also, has attracted a lot of researchers including Ramayah et al. (2005), Mutula \& Brakel (2006), Molla and Licker (2005) and Huang et al. (2004) [7] [19]-[21]. Their e-readiness tools can be considered as a generic by many as one e-readiness tool assessments that are applicable to a country level and the industrial level. However, since the studies are not focus on B2B e-commerce, the tool cannot be used effectively for B2B e-commerce readiness assessment. The models 
also do not put into consideration the barriers that inhibit the implementation of technology in organizations. Specific indices of barriers under each e-readiness dimension are able to give a more clear theoretical foundation of e-readiness level.

Another study by [22] produced a tool to measure e-commerce readiness in the automotive industry through the case study approach of the large company names Iran Khodro Industrial Group and its related supply chain. The study adopted the VERDICT model of Ruikar (2006) [23], to assess the e-commerce readiness in B2C relationships. However, since the focus is mostly on large companies, the measurement might not be compatible with the needs of SMEs. Another study by Zakaria \& Janom (2011) and Fathian et al. (2008) [24] [25], added further insight in understanding the widespread adoption of e-commerce in SMEs in developing countries. Even though both studies provide views on multiple perspectives of e-commerce adoption at industrial level, the limitations of organizational and environmental indicators is not sufficient enough to understand technology adoption among SMEs in developing countries.

In short, the existing literature review with regard to e-readiness in developing countries, showed the positive and negative aspects of such measures. Even though most e-readiness models provide a useful overview of the significant factors of e-readiness, they do not completely provide meaningful multidimensional measures that are specific for SMEs in developing countries. Another limitation of existing research is related to the research scope which mostly focuses on large companies indicators which has limited power in explaining how and what level of infrastructure development affects the SME's decision to adopt B2B e-commerce. The formulation of e-commerce readiness models also have so far been mainly addressed from either the perspective of the individual firm or the perspectives of a whole industry or the perspectives of country e-readiness. This seems to be a serious shortcoming since SMEs need proper e-readiness assessment tool to identify the real issues and drivers of B2B e-commerce and its success. Therefore, it is necessary to make an attempt to develop model that able to measure the B2B e-commerce maturity assessment specific from SMEs perspective.

\section{Development of B2B E-Commerce Maturity Assessment Application}

Currently most of the e-readiness tools use different definitions and different techniques of measurement that lead to different concepts and ideas as well as their practical applications and implications in e-readiness areas [26]. The definition of e-readiness is very much depends on purpose and scope of research in order to make sure the variables measure what they are supposed to measure. Thus, in this study e-readiness or e-maturity is defined as the degree to which an organization is prepared to participate in the digital B2B transactions through considering various e-readiness success factors and challenges. Since the words readiness and maturity are believed to portray the same meaning, both will be used interchangeably in this paper.

In the development of B2B e-commerce readiness assessment application, sequential exploratory design involving qualitative and quantitative approaches was used. Using this method, theories can be developed qualitatively and tested quantitatively [23]. A systematic two-stage approach was also adopted in the development process. The first stage involved the development of the B2B e-commerce readiness dimensions and indicators which were later operationalized into the B2B e-commerce readiness assesssment application. The second stage involved development and evaluation of a prototype application. The stages are explained below.

\subsection{The Development of B2B E-Commerce Maturity Dimensions}

As e-commerce is a multi-disciplines area of research, the discussions of e-commerce had been viewed from several perspectives using different models which are designed to examine different aspect of e-commerce. For example, some models examine the external environment of firms [25] [27], some are focused on technology aspect [26] [28], other studies focus on social and behavioural aspects [29]-[34], some focus on organizational factors [9] [35]-[39], and the others used the combination on any of these perspectives [11] [40]-[45]. Thus, considering the importance to identify variables and factors that are able to provide multidimensional insights on B2B e-commerce readiness, it is critical for researcher to identify e-readiness indicators that cover the internal and external organization factors.

Through extensive literature review analysis on various publications in related to B2B e-commerce area, appropriate theory and model to support and enforce a competitive e-readiness approach have been identified. However, according to Amit \& Zott (2001) [46], as cited by Mansfield \& Fouries (2004) [47], since each theo- 
retical framework and model has its own limitations when applied in a context of highly interconnected electronic markets, the exploitation and integration of different theoretical views approach are normally used. Theories and frameworks also probably need to be tailored to the type of technology and its adoption context since it is difficult to develop a unifying, one-size-fits-all theory related to technology adoption. Considering the perspective of this research, the integration of different theoretical views consists of resources based view (RBV), Technology-Organization-Environment (TOE) model, Technology acceptance model (TAM), Technology Readiness Index (TRI) and Diffusion of innovations (DOI) have been employed.

The theories are used to investigate the factors that determine the e-readiness and its stages. Even though each theory and model is focusing on different aims and objectives, there are some commonalties which exist among the theories that can assist in enriching the B2B e-commerce readiness model developed in this study. Each of the principle themes contributes in some way to further explain and justify research strategies related to ereadiness assessment in SMEs. Based on the theories, an extensive literature review of more than thirty publications related to B2B e-commerce are gathered which are used to build e-readiness assessment indicators model. From the review, analysis and classification of related factors in these publications, three dimensions emerged as critical to the B2B e-commerce readiness which is individual, organizational and environmental dimensions. Under these three dimensions, eight aspects are initially identified and operationally defined. Each aspect contains their own critical success factors and issues. The conceptual definitions and quantity measured under each aspect are being discussed in Table 1 .

For the sake of completeness and to ensure the validity of the B2B e-commerce readiness integration scale, expert evaluation is used. The subject matter expert should provide feedback in relevance to the significance and weight age of each critical factor indicator of $\mathrm{B} 2 \mathrm{~B}$ e-commerce readiness. Thus, in order to ensure expert is able to provide an overview and insight of B2B e-commerce from different perspectives. the selection of the experts is based on three criteria such as: 1) involve in the strategic planning, development, monitoring and the marketing of B2B e-commerce application 2) knowledgeable and have experience related to SMEs 3) willingness to participate in the research. Based on these criteria, six management executives from six different organizations were selected and interviewed using purposive sampling. The management executives included CEO, CIOs, Vice President, Project Directors and senior executive who in charge of B2B e-commerce projects SMEs. The reviews from experts have provided tentative evidence of the reliability and validity of the B2B e-commerce readiness constructs and indicators. In addition, in order to identify specific weight for each indicator, the Analytical Hierarchy Process (AHP) was used. According to AHP, the more important is the indicator, the greater the weight age will be. Due to space limitation of the paper, the relative weight for each indicator is not provided but can be refereed in Janom and Zakaria (2010) [48]. Overall there are 59 critical success factors and 30 issues being identified. However, to identify the e-readiness stages, each dimension value is measured by calculating the scores of the indicators classified under them. This was done through, deducting the total AHP score of critical success factors with the total AHP score of issues. Then the range of score for each aspect is obtained by dividing the range of e-readiness scores by four which represent the four level of e-readness. Table 2 shows the matrix of the range of index score for all $\mathrm{B} 2 \mathrm{~B}$ e-commerce readiness aspects for each e-readiness stages.

The model was then operationalized into questionnaire form to be embedded into B2B E-commerce Maturity Assessment Application (BeMA).

\subsection{B2B E-Commerce Maturity Assessment Web Development}

The B2B e-commerce Maturity Application (BeMA) is the web-based prototype application that able to assess the B2B e-commerce maturity of SME. The BeMA is designed using System Development Life Cycle (SDLC) method. In designing the navigational structure, several important features have been identified and constructed based on Austin et al. (2008) and Arshad et al (2008) [49] [50]. Table 3 shows the listing of 7 important features of BeMA.

The BeMA home page provides brief explanation on the purpose and benefits of application to the users. On the left hand side of the screen, researcher provides list of menu that user can select. User can click any menu they want and they will be directed to a new page. However, for the first time user, researcher strongly suggest for the respondent to select the first two menu options of "B2B e-commerce Maturity Dimension" and "Maturity levels" to get a better understanding on the subject matter. The main page also shows the list of link to other pages including B2B e-Commerce Maturity Dimension, Maturity levels and Start assessment. 
Table 1. Conceptual and quantity measured.

Conceptual Definition Quantity Measured

\section{Personal traits:}

Personal traits address the motivation, personality and characteristics of owner/top management regarding the adoption of B2B EC.

\section{Organizational features:}

This is based on availability of organization to fulfill the requirements of B2B EC in terms of technology affordability, policies, procedures, innovation culture, strategies and visions, governance as well top management commitment.

\section{Competency:}

This considers the social and cultural aspects encompasses of competencies, relationships, exposure and skills of employees in organization with regards to $\mathrm{B} 2 \mathrm{~B} \mathrm{EC}$ technology

Technology:

The variables include the availability of technology infrastructure, the flexibility and the capability of existing organizational system.

\section{Business Process:}

This cover the practices, actions, business process, the flexibility, working rules, collaborations and communications, procedures that compliment and accommodate activities within and between organizations.

\section{Market forces:}

This construct includes the e-readiness assessment on related suppliers and competitors with regards to $\mathrm{B} 2 \mathrm{~B} \mathrm{EC}$. The constructs include the integration, collaboration and cooperative norms among trading partners.

\section{Supporting industries:}

The attributes involve the support of industries on the availability of telecommunications, financial, trust enablers, IT industry and consultant services.

\section{Government:}

This involves the conduciveness of the B2B EC climate, economic, financial support, national infrastructure conditions and e-government initiatives
Does the top management have positive attitudes towards B2B e-commerce (EC)? Do the issues related to personal traits retard the B2B EC of the company?

Does the organization have set up a suitable and effective goals and strategies on B2B EC?

Does the governance model emphasize on the effective management of B2B EC?

Do the policies and procedures are sufficient to meet B2B EC?

Does the top management provide sufficient support for B2B EC development?

Does the organization culture encourage technology innovation?

Do the issues related to organizational readiness retard the B2B EC readiness of the company?

Do the employees are capable to adopt and manage B2B EC technology?

Does the organization have internal B2B EC expertise?

Does the organization provide training and initiatives related to $\mathrm{B} 2 \mathrm{~B} \mathrm{EC}$ ?

Do the issues related to competencies retard the B2B EC

readiness of the company?

Does the available internal technology meet the requirements of B2B EC?

Does internal technology meet the security requirements of B2B EC?

Does the organization have B2B system that emphasis on e-service quality?

Do the issues related to technology retard the B2B EC readiness of the company?

Does the existing process need a comprehensive change?

Do the communications and integration within and between organizations enough to support and regulate $\mathrm{B} 2 \mathrm{~B} \mathrm{EC}$ ?

Does the barrier related to business process retard the $\mathrm{B} 2 \mathrm{~B} \mathrm{EC}$ readiness of the company?

Do the company's initiatives fit well with industry's development? Does the company's value chain fits with the B2B EC initiative?

Does company impose agreement and programs to enhance relationships with trading partners?

What are the initiatives and efforts taken to get participation from trading partners? Do the issues related to market forces retard the B2B EC readiness of the company?

Does telecommunication industry provide appropriate service and support?

Does financial industry provide appropriate service and support?

Do courier and logistic industries provide appropriate service and support?

Does industry legal expertise able to manage B2B EC related issues?

Do the issues related to supporting industries retard the B2B EC readiness of the company?

Does B2B EC readiness is a national priority?

How effective the national laws and policies related to B2B EC?

What are the available initiatives to foster B2B EC development?

Do the issues related to government readiness retard the $\mathrm{B} 2 \mathrm{~B} \mathrm{EC}$ readiness of the company?

However, the main body of the application comprises of the B2B e-commerce maturity questionnaire which is distributed over eight pages which one page represents one e-readiness aspect. In order to gauge the B2B e-commerce maturity score, the measurements are obtained through inferences drawn from the various scores of indicators compose under each aspect.

Unlike other models that rely entirely on captured data from the respondents' perceptions that may be rather subjective, this model is different as it weights each factor according to impact on the overall organization. The score reflects the real situations of the organization. The relative weights of all selection criteria were used to calculate the scores for B2B e-commerce maturity of the organization. As shown in Figure 1, researcher uses a 5 point likert scale of: 1). strongly not agree 2). not agree 3). neutral, 4). agree, and 5). strongly agree. The assessment is based on respondent's agreement on the availability of the e-readiness indicators in the organization which are required for a successful B2B e-commerce implementation. The organization will assess their readiness for each criterion based on the above likert scale and calculated the final score for e-readiness measurement. 


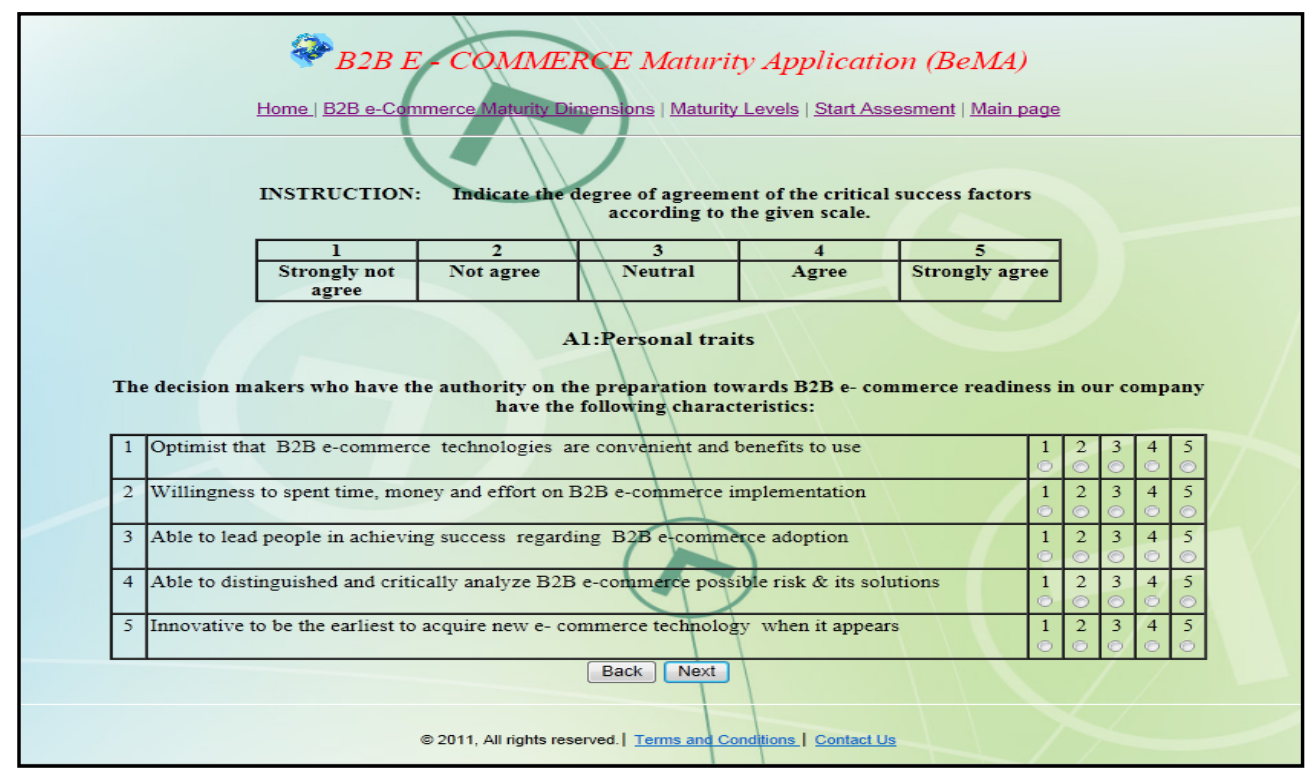

Figure 1. BeMA questionnaire using 5 point likert scale.

Table 2. Range of index score.

\begin{tabular}{ccccc}
\hline Indicators/stages & Stage 1 & Stage 2 & Stage 3 & Stage 4 \\
\hline Personal traits & Below (-2) & $(-2.01)-0$ & $0.01-2$ & $2.01-4$ \\
Organizational features & Below 4 & $4.01-9$ & $9.01-14$ & $14.01-19$ \\
Competency & Below 2 & $2.01-6$ & $6.01-10$ & $10.01-14$ \\
Technology & Below 2 & $2.01-6$ & $6.01-10$ & $10.01-14$ \\
Business process & Below (-2) & $(-2.01)-0$ & $0.01-2$ & $2.01-4$ \\
Market forces & Below (-2) & $(-2.01)-0$ & $0.01-2$ & $2.01-4$ \\
Supporting industries & Below 0 & $0.01-3$ & $3.01-6$ & $6.01-9$ \\
Government & Below (-2) & $(-2.01)-0$ & $0.01-2$ & $2.01-4$ \\
Overall & Below 2 - 24 & $2.01-24$ & $24.0-48$ & $48.01-68$ \\
\hline
\end{tabular}

Table 3. Important features for BeMA.

\begin{tabular}{|c|c|c|}
\hline No & Page classification & Features \\
\hline 1. & Home & $\begin{array}{l}\text { Introduction } \\
\text {-Explain the purpose of the application } \\
\text {-Explain the benefits of the e-readiness assessment to the organization } \\
\text {-The page also provide link to assess e-readiness }\end{array}$ \\
\hline 2. & $\begin{array}{l}\text { B2B e-commerce } \\
\text { maturity dimension }\end{array}$ & $\begin{array}{l}\text {-Provide brief explanation on the B2B e-commerce readiness } \\
\text {-Describes all eight readiness dimensions namely personal traits, organizational features, } \\
\text { competency, technology, business process, market forces, supporting industries and government. }\end{array}$ \\
\hline 3. & Maturity levels & -Provide brief description of all four maturity stages from stage 1 to stage 4 . \\
\hline 4. & Maturity Assessment & $\begin{array}{l}\text {-Enables data capture activities and prompting results and analysis on the assessment } \\
\text {-Provides strategic solutions based on the result obtained }\end{array}$ \\
\hline 6. & Contact us & -Provide researchers name and contact address to establish authority and credibility of the researcher. \\
\hline 7. & Terms and conditions & -Establish respondent confidentiality and privacy \\
\hline
\end{tabular}


On successful completion of the questionnaire, users are presented with a report that summarises their overall maturity level as well as e-readiness stage for each aspect (refer Figure 2). This allows companies to focus on, and improve on, those specific aspects. This maturity assessment report includes data in textual formats. Once the results of the assessment are shown, users are given a series of recommendations based on their maturity stage levels. The recommendations can help SMEs to progress to the next maturity level. Overall it is advisable for SMEs to focus on seven strategy recommendations as below:

- Develop positive perceptions and attitudes towards B2B e-commerce through providing motivational development programs to develop self-efficacy, motives, needs, capabilities, and expectations on B2B e-commerce among top management and employees.

- Increase top managemnet support through encouraging top management to equip themselves with managerial and technical knowledge on B2B e-commerce business model, concepts, process, policies, procedures and solutions so that the project will have high priority and receives the required financial resources and attention.

- Provide appropriate technical and management training courses which emphasize on acquisition of skill of know-how and know-why to increase knowledge, skill and positive perception on B2B e-commerce technology. The training modules also should reflect differences between types of organization, functional orientation, level of personnel and level of employee's competencies.

- Increase technology resources and set priority. Organization needs to be equipped with the telecommunication networks, backbones, switches, routers, multiplexers, as well as internet with broader bandwidth that include all of its parts.

- Continual improvement on business process and products through thorough understanding of their product transactions and specifications. This will allow companies to better design the B2B e-commerce process and offer greater value to buyers and sellers.

- Mutual beneficial relationships with trading partners, supporting industries and government through encouraging open communication and cooperation between different functional departments which can increase business process effectiveness and efficiency The risk-sharing agreements and strategic alliances between smaller players and industry leaders can also increase prominence in the strategy and able SMEs to compete more effectively with large players.

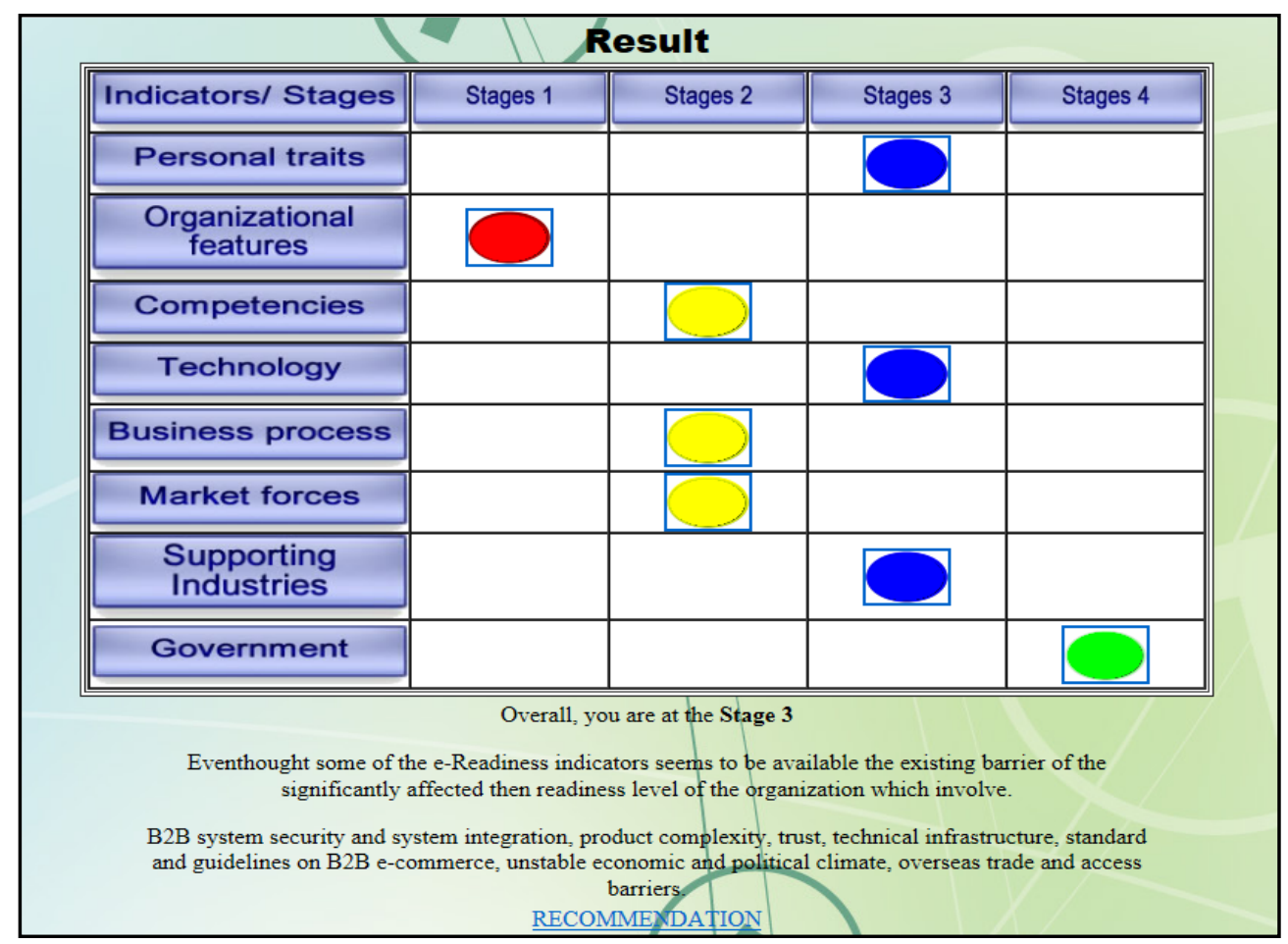

Figure 2. Result of e-readiness assessment stages. 
- Continuous review on B2B e-commerce application and systems. For SMEs that are ready to introduce B2B e-commerce application or those already have B2B e-commerce application in place, it advisable for them to create a more fault-tolerant atmosphere to further encourage success in $\mathrm{B} 2 \mathrm{~B}$ e-commerce development. They need to continuously review B2B policies, procedures, training modules, and supply chain business operation which is an impediment to the further development of B2B e-commerce.

\section{BeMA Evaluation}

Even though the application has been derived from solid research base, the application evaluation is needed as it is a proactive measure to ascertain its validity, acceptability, applicability and usability. Thus, in order to ensure the practicality and the usefulness of the application developed, there is a need to verify the model and its feasibility. Taking into account the satisfaction of user requirements, the idea of validating the application is generally taken to prove that it works satisfactorily for SMEs other than those from whose data was derived. In addition, the validation through users should demonstrate the feasibility, practicality and integrity of the application.

To facilitate the evaluation process, thirty-five SMEs from agro-based industry were given hands-on usage of the application prototype developed in this study. SMEs as a potential user of the application were selected through convenience sampling method based on the listing in SME Corp web sites, Members of AgriBazar Portal Malaysia's (both are the latest update listing of June 2010) and Halal Directory 2008. The target group of this application evaluation and validation exercise was either the CEO, owner of the organization, or project manager who is in the best position to relate to the subject matter. As mentioned, the e-readiness assessments are done through the BeMA application, which the users were asked to enter their input regarding B2B e-commerce readiness elements into the questionnaire set in the application. On completion of the assessment and certification exercise, respondents were given a standard questionnaire evaluation form covering areas of functionality, usability, accuracy, attractiveness and benefits of the model. Figure 3 illustrates the flow of the process.

Respondents were encouraged to include any additional suggestions enhancing the application. However, if the respondents do not agree with the e-readiness assessment results they may give comment and suggestion in the form provided. The evaluation relies on the judgement of the respondents as to whether or not he/she agrees with the statements in the context of their organizations. By looking at the e-readiness analysis and its solutions provided by the application, users are able to assess whether the application is justified to be the proficient tool to measure B2B e-commerce maturity in SME in the real world environment. The respondents need to ensure that their responses are consistent and reflected throughout.

The extent to which the respondent agrees or disagrees with the statement is graded on a scale of 1 to 5 , where $1=$ Strongly Disagree, $2=$ Disagree, $3=$ Neither Agree/Disagree or No Opinion, $4=$ Agree and $5=$ Strongly Agree. An average score was calculated for each element. The results from the assessment of the model revealed that in terms of average and standard deviation score, all respondents basically agree on the usability, effectiveness, attractiveness, accuracy and benefits of the application. In terms of frequency analysis about 28 (80\%) SMEs agree that the application is usable to assess organization e-readiness. Only one respondent indicated neither agree or disagree on the usability of the model, and the other $6(17 \%)$ strongly agreed on the usability of the model. From the perspective of model effectiveness, about 29 (82\%) SMEs agreed on the effectiveness of the model, while $5(14 \%)$ of the respondents strongly agreed that the e-readiness assessment results are easy to understand and effectively highlight the areas of readiness that company need to address. The results also shows that most respondents $(70 \%)$ are satisfied with the e-readiness analysis results and thought that the e-readiness results accurately reflect the current B2B e-commerce readiness level in the company. While the other 4 (11\%) SMEs, strongly agreed on the accuracy of the e-readiness assessment results. However, about $6(17 \%)$ SMEs neither disagree or agree. The evaluation findings also highlighted that about $29(83 \%)$ of the SMEs agreed that the resolutions suggested in the application are able to improve the maturity level of B2B e-commerce. Only

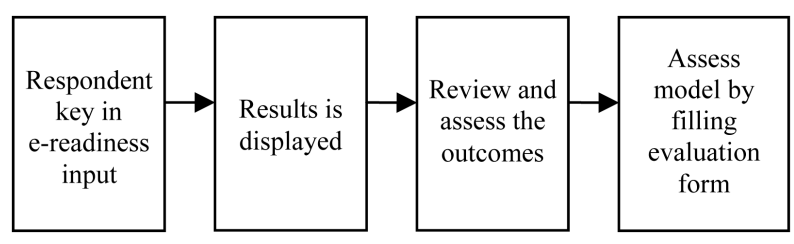

Figure 3. The flow of the process. 
about $1(3 \%)$ of SMEs neither agree or disagree on the resolutions provided to them, while the other $14 \%$ strongly agreed that the suggestions are comprehensive and meaningful. In terms of the benefits of the application, majority (80\%) of the SMEs agree that the application is beneficial to the SME as it gives a clear result of an organisation's strengths and weaknesses regarding its readiness for B2B e-commerce, about 3 SMEs (9\%) strongly agree while the other $4(11 \%)$ neither disagree or agree. The results provided from the assessment, allowed the respondent to do comparisons and to assess whether the application reflects the real B2B e-commerce maturity of their organizations. On the whole, the evaluation results are encouraging and most respondents verify the validity of the application. They are also enthusiastic for future use of BeMA. From the evaluation assessment it can be concluded that:

- The application is usable as it addresses all aspects of B2B e-commerce that SMEs need to consider to achieve e-readiness.

- The application is easy to understand as it provides easy to understand reports and highlight e-readiness aspects that company need to address on.

- The application accurately portrays the current maturity level of the organization which reflect the integrity of the application as a valuable maturity assessment tool.

- The resolutions provided in the application are acceptable to be used as guidelines for organization to achieve a higher maturity level. However, further research on B2B e-commerce readiness best practices from expert advices will add more value to the application.

- The application is also beneficial to SME as it highlight organisations' strengths and weaknesses. Through the application, SME can strategize and plan their resources effectively with respect to B2B e-commerce implementation. In general, the evaluation exercises have demonstrated the practicality and the integrity of the application.

\section{Conclusions}

The research intends to provide maturity model as a practical guidance to other researchers. In order to ensure its successfulness, the systematic research process of the B2B e-commerce maturity model was used. The model was generated in conceptual form, which was subsequently developed through evaluation from subject matter experts in B2B e-commerce. The model has been refined and improved by incorporating the significance e-readiness factors which were measured by the index score. However, to prove that the model provides an accurate and well structured representation of SME's environment, BeMA validation assessment by SME was done. Overall, the evaluation results are encouraging and most respondents verified the validity of the model. They are also enthusiastic for future use of BeMA. Thus, based on the validation and assessment results, it is worth pointing out that the model and the application have proved its practicality in SMEs context.

The research also proved that the theory and findings have thus supported the B2B e-commerce maturity model. With the adoption of the proposed B2B e-commerce maturity model, SME is hoped to be better prepared to manage B2B business transaction in a more efficient way. However, due to the growing complexity of SME business environment, the indicators focused in this research should not be treated as definitive for SME yet. Further analysis of organization capability and their impact on the conditions of the environment are needed in order to increase the granularity of the B2B e-commerce maturity model.

\section{References}

[1] Doern, R. (2009) Investigating Barriers to SME Growth and Development in Transition Environments: A Critique and Suggestions for Developing the Methodology. International Small Business Journal, 27, 275-305.

http://dx.doi.org/10.1177/0266242609102275

[2] Mutula, S.M. (2005) Assessment of The E-Readiness of Small and Medium Sized Enterprises in the ICT Sector in Bostawana, with Special Reference to Information Access. Unpublished Thesis Ph.D. University of Johanesburg, Johannesburg.

[3] OECD (2001) Enhancing SME Competitiveness. The OECD Bologna Ministerial Conference. 14-15 June 2001.

[4] Chong, W.K., Tadjouddine, E.M., Shafaghi, M. and Tan, B.L. (2011) Automated Mechanism Design for B2B ECommerce Models. International Journal of Trade, Economics and Finance, 2, 87-91. http://dx.doi.org/10.7763/IJTEF.2011.V2.83

[5] Avantikumar (2010) NIM2010 to focus on SMEs, E-Commerce and Global Marketing. Computerworld, 20, 1-2. 
[6] Archer, N., Wang, S. and Kang, C. (2009) Barriers to the Adoption of Online Supply Chain Solutions in Small and Medium Enterprises. Supply Chain Management: An International Journal, 13, 73-82. http://dx.doi.org/10.1108/13598540810850337

[7] Huang, L. (2006) Building up a B2B E-Commerce Strategic Alliance Model Under an Encertain Environment for Taiwan's Travel Agencies. Tourist Management, 27, 1308-1320. http://dx.doi.org/10.1016/j.tourman.2005.06.005

[8] Grigoryan, A.A. (2006) B2B E-Commerce in the United States, Europe and Japan: A Comparative Study. Journal of Applied Sciences, 6, 2131-2140. http://dx.doi.org/10.1016/j.tourman.2005.06.005

[9] Engstrom, A. and Sangari, E.S. (2007) Assessment of Business-To-Business (B2B) E-Marketplaces Performance. Unpublished Doctoral Thesis, Lulea University of Technology, Luleå.

[10] Zhou, P., Ang, B.W. and Poh, K.L. (2007) Composite Indicators for Measuring Systems Performance: An Information Theoretical Aggregation Approach. Proceedings of Asia-Pacific Systems Engineering Conference, Singapore, 23-24 March 2007.

[11] Gunasekaran, A., McGaughey, R.E., Ngai, E.W.T. and Rai, B.K. (2009) E-Procurement Adoption in the Southcoast SMEs. International Journal Production Economics, 122, 161-175. http://dx.doi.org/10.1016/j.ijpe.2009.05.013

[12] Ang, C.J., Yew, O.K. and Ramasamy, R. (2010) Enhancing Competitiveness of ICT Industry: PIKOM's Policy Advocacies and Interventions. Ramachandran Ramasay (Pnyt.). ICT Strategic Review 2010/11 E-Commerce for Global Reach, 1-40. PIKOM, Petaling Jaya.

[13] Wang, T-C. and Lin, Y-L. (2009) Accurately Predicting the Success of B2B E-Commerce in Small and Medium Enterprises. Expert System with Applications, 36, 2750-2758. http://dx.doi.org/10.1016/j.eswa.2008.01.033

[14] Wahab, A.A., Saleh, S. and Razak, M.A. (2010) Uptake of E-Commerce in Malaysia: A Policy Perspective. Ramachandran Ramasamy (Pnyt.). ICT Strategic Review 2010/11 E-Commerce for Global Reach, 41-66. PIKOM, Petaling Jaya.

[15] Yusoff, A.R. (2010) Overview of E-Commerce Adoption among SMEs in Malaysia. Seminar dan Pameran Sistem Penyelesaian Elektronik 2010 Transformasi Peniagaan Melalui E-Dagang. Subang, Selangor, 16 March 2010.

[16] Aziz, N.M. and Salleh, H. (2011) Managing Organization/Business Readiness towards IT/IS Implementation: A Model Comparison. Australian Journal of Basic and Applied Sciences, 5, 215-221.

[17] Dada, D. (2006) E-Readiness for Developing Countries: Moving the Focus from the Environment to the Users. The Electronic Journal on Information Systems in Developing Countries, 27, 1-14.

[18] Bridges.org (2001) Comparison of E-Readiness Assessment Models. Http://www.internetpolicy.net/readiness/ereadinesscomparison.pdf

[19] Ramayah, T., Yan, L.C. and Sulaiman, M. (2005) SME E-Readiness in Malaysia: Implications for Planning and Implementation. SASIN Journal of Management, 11, 103-120.

[20] Mutula, S.M. and van Brakel, P. (2006) An Evaluation of E-Readiness Assessment Tools with Respect to Information Access: Towards an Integrated Information Rich Tool. International Journal of Information Management, 26, 212223. http://dx.doi.org/10.1016/j.ijinfomgt.2006.02.004

[21] Molla, A. and Licker, P. (2005) E-Commerce Adoption in Developing Countries: A Model and Instrument. Information \& Management, 44, 877-899. http://dx.doi.org/10.1016/j.im.2004.09.002

[22] Aminali, P. (2007) E-Readiness Assessment within the Iran's Automative Industry Case of Iran Khodro Industrial Group. Master Thesis, Department of Business Administration and Social Sciences, Lulea University of Technology, Lulea.

[23] Ruikar, K., Anumba, C.J. and Carrillo, P.M. (2006) VERDICT-An E-Readiness Assessment Application for Construction Companies. Automation in Construction, 15, 98-110. http://dx.doi.org/10.1016/j.autcon.2005.02.009

[24] Zakaria, M.S. and Janom, N. (2011) Developing and Validating Readiness Measures of Inter-Organizational E-Commerce on SMEs. Journal of Internet Banking and Commerce, 16.

[25] Fathian, M., Akhavan, P. and Hoorali, M. (2008) E-Readiness Assessment of Non-Profit ICT SMEs in a Developing Country: The Case of Iran. Technovation, 28, 578-590. http://dx.doi.org/10.1016/j.technovation.2008.02.002

[26] Hanafizadeh, P., Moosakhani, M. and Bakhshi, J. (2009) Selecting the Strategic Best Practices for Business Process Redesign. Business Process Management Journal, 15, 609-627. http://dx.doi.org/10.1108/14637150910975561

[27] Chong, S. (2008) Success in Electronic Commerce Implementation: A Cross-Country Study of Small and Medium Sized Enterprises. Journal of Enterprise Information Management, 21, 468-492. http://dx.doi.org/10.1108/17410390810904247

[28] Borges, M., Hoppen, N. and Luce, F.B. (2009) Information Technology Impact on Market Orientation in E-Business. Journal of Business Research, 62, 883-890. http://dx.doi.org/10.1016/j.jbusres.2008.10.010

[29] Bunduchi, R. (2007) Trust, Power and Transaction Costs in B2B exchanges-A Socio-Economic Approach. Industrial 
Marketing Management, 1-13.

[30] Canavari, M., Rivaroli, S. and Mater, A. (2006) Prioritizing Trust Factors in an Agri-Food B2B E-Commerce Environment. Proceedings of the 99th EAAE Seminar Trust and Risk in Business Network, Bonn, 8-10 February 2006.

[31] Lai, J.Y., Ong, C.S., Yang, C.C. and Wang, C.T. (2008) Assessing and Managing Employee Readiness for Embracing E-Business. Proceedings of the Special Interest Group Management Information System-Computer Personnel Doctoral'08, Charlottesville, Virginia, 3-5 April 2008, 79-87.

[32] Lai, J.Y. and Ong, C.S. (2010) Assessing and Managing Employees for Embracing Change: A Multiple-Item Scale to Measure Employee Readiness for E-Business. Technovation, 30, 76-85. http://dx.doi.org/10.1016/j.technovation.2009.05.003

[33] Lin, C.H. (2007) The Effects of Technology Readiness on the Formation of E-Service Value. Proceedings Portland International Center for Management of Engineering and Technology, PICMET 2007, Portland, 5-9 August 2007, 1811-1817.

[34] Uzoka, F.M.E. and Shemi, A.P. (2007) Behavioral Influences on E-Commerce in a Developing Country Context. The Electronic Journal of Information Systems in Developing Countries, 31, 1-13.

[35] Molla, A. and Peszynski, K. (2011) E-business in Agribusiness: Investigaing the E-readiness of Australian Horticulture Firms. International Journal of Information Communication Technologies and Human Development, 1-19.

[36] Asporth, V. and Nystrom, C.A. (2008) Communication and Information Exchange among SMEs and Their Local Environment. Journal of Organisational Transformation and Social Change, 5, 175-189. http://dx.doi.org/10.1386/jots.5.2.175_1

[37] Laosethakul, K. and Boulton, W. (2007) Critical Success Factors for E-Commerce in Thailand: Cultural and Infrastructural Influences. The Electronic Journal of Information Systems in Developing Countries, 30, 1-22.

[38] Lee, S.M., Lim, S.B. and Soriano, D.R. (2009) Suppliers' Participation in a Single Buyer Electronic Market. Group Decision and Negotiation, 18, 449-465. http://dx.doi.org/10.1007/s10726-008-9136-8

[39] Shaltoni, A.M. and West, D.C. (2010) The Measurement of E-Marketing Orientation (EMO) in Business-to-Business Markets. Industrial Marketing Management, 39, 1097-1102. http://dx.doi.org/10.1016/j.indmarman.2009.06.011

[40] Tan, J., Tyler, K. and Manica, A. (2007) Business-to-Business Adoption of E-Commerce in China. Information \& Management, 44, 332-351. http://dx.doi.org/10.1016/j.im.2007.04.001

[41] Haghighi, M., Divandari, A. and Keimasi, M. (2010) The Impact of 3D E-Readiness on E-Banking Development in Iran: A Fuzzy AHP Analysis. Expert Systems with Applications, 37, 4084-4093. http://dx.doi.org/10.1016/j.eswa.2009.11.024

[42] Heijungs, R., Huppes, G. and Guinee, J.B. (2010) Life Cycle Assessment and Sustainability Analysis of Products, Materials and Technologies: Toward a Scientific Framework for Sustainability Life Cycle Analysis Polymer Degradation and Stability. Polymer Degradation and Stability, 95, 422-428.

[43] Jalal, S.F. (2007) Simplifying Procurement Process through E-Commerce in B2B Market of Iran. Unpublished Master Thesis, Department of Business Administration, Lulea University of Technology, Lulea.

[44] Rosenzweig, E.D. and Roth, A.V. (2007) B2B Seller Competence: Construct Development and Measurement Using a Supply Chain Strategy Lens. Journal of Operations Management, 25, 1311-1331. http://dx.doi.org/10.1016/j.jom.2007.01.007

[45] White, A., Daniel, E., Ward, J. and Wilson, H. (2007) The Adoption of Consortium B2B E-Market Places: An Exploratory Study. Strategic Information Systems, 16, 71-103. http://dx.doi.org/10.1016/j.jsis.2007.01.004

[46] Amit, R. and Zott, C. (2001) Value Creation in E-Business. Strategic Management Journal, Special Issues: Strategic Entrepreneurship: Entrepreneurship Strategies for Wealth Creation, 22, 493-520.

[47] Mansfield, G.M. and Fourie, L.C.H. (2004) Strategy and Business Models-Strange Bedfellows? A Case for Convergence and Its Evolution into Strategic Architecture. South African Journal of Business Management, 35, 35-44.

[48] Janom, N. and Zakaria, M.S. (2010) The Development of B2B E-Commerce Readiness Assessment for SMEs: Identification of Barriers Using AHP Method. International Journal of Information Science and Management, Special Issues, 61-76.

[49] Austin, T.M., Richter, R.R. and Reinking, M.F. (2008) A Primer on Web Surveys. Journal of Allied Health, 37, 180186.

[50] Arshad, N.H., Ahmad, F., Janom, N. and Mohamed, A. (2008) Online Transportation Services Guideline for Service Quality. WSEAS Transactions on Business and Economics, 5, 195-203. 